\title{
Refractory Childhood Hodgkin Lymphoma
}

National Cancer Institute

\section{Source}

National Cancer Institute. Refractory Childhood Hodgkin Lymphoma. NCI Thesaurus.

Code C115458.

Hodgkin lymphoma that occurs during childhood and is resistant to treatment. 